УДК 316

$10.17213 / 2075-2067-2020-5-74-83$

\title{
ИНСТИТУЦИОНАЛЬНЫЕ БАРЬЕРЫ РАЗВИТИЯ ЭКОЛОГИЧЕСКОГО ПОВЕДЕНИЯ РОССИЙСКОЙ МОЛОДЁЖИ
}

\author{
(C) 2020 г. B. A. Захарова \\ Крымский филиал Федерального научно-исследовательского \\ социологического центра РАН, г. Симферополь, Россия
}

Целью исследования является изучение институциональных барьеров развития экологического поведения российской молодёжи.

Методологическую базу исследования представляет синтез современных методологических подходов: структурно-функиионального институционализма, «понимающей» (культурсочиологии) сочиологии, рискологического и сочииально-воспроизводственного направлений сочиологических исследований.

Результаты исследования. К числу ключевых барьеров, существенно тормозящих развитие экологического поведения в среде российской молодёэи, относятся структурные детерминанты российской экономики, не в последнюю очередь связанные с системными проблемами её модернизации. По-прежнему в российском обществе не в полной мере может быть реализована глобальная экологическая повестка, актуальная для наиболее развитьх стран. На сегодняшний день государственная стратегия России, несмотря на иельй ряд деклараций экологического характера, всё-таки в большей степени нацелена на адаптаичию в условиях санкционного режима и сохранения статуса страны в качестве крупнейшего экспортера углеводородов.

Перспективу исследования составляет дальнейшее изучение специфики преодоления институциональных барьеров развития экологического поведения российской молодёжи.

Ключевые слова: молодежь; российское общество; экологическое поведение; институцииональные барьеры.

\section{INSTITUTIONAL BARRIERS TO THE DEVELOPMENT OF ENVIRONMENTAL BEHAVIOR OF RUSSIAN YOUTH}

(C) 2020 V. A. Zakharova

\section{Crimean Branch of the Federal Research Sociological Center, Russian Academy of Sciences, Simferopol, Russia}

The aim of the study is to study institutional barriers to the development of environmental behavior of Russian youth.

The methodological basis of the research is a synthesis of modern methodological approaches: structural and functional institutionalism," understanding " (cultural sociology) sociology, risk-based and socio-reproductive areas of sociological research.

Research result. Among the key barriers that significantly hinder the development of environmental behavior among Russian youth are the structural determinants of the Russian economy, not least related to the systemic problems of its modernization. The global environmental 
agenda, which is relevant for the most developed countries, is still not fully implemented in Russian society. To date, the state strategy of Russia, despite a number of environmental declarations, is still more aimed at adapting to the sanctions regime and preserving the country's status as the largest exporter of hydrocarbons.

The perspective of the research is to further study the specifics of overcoming institutional barriers to the development of environmental behavior of Russian youth.

Key words: youth; Russian society; environmental behavior; institutional barriers.

Введение. Экологизация поведения российской молодёжи, то есть его трансформация в сторону большей ответственности в отношении природных объектов и окружающей среды, его рационализация и позитивная оценка имеющихся в стране природных благ имеет не только границы, но и барьеры, препятствующие экологической социализации молодёжи, либо существенно-замедляющей её темпы. Стремление беречь собственную природу сталкивается с ограничениями (барьерами) природного, социально-экономического и техногенного свойства, которые могут тормозить социальные практики, способствующие экологизации поведения современной молодёжи [1]. При этом важно учитывать, что размеры нашей страны и наличие в её составе самых разнообразных регионов демонстрируют многообразие экологических проблем и способов их преодоления.

Барьеры, препятствующие внедрению экологической культуры и распространению экологического поведения, зачастую связываются с исторически сложившимися в течение десятилетий или даже целых веков особенностями системы управления российским социумом. Государственные институты в России прежде всего связаны с вертикалью власти и заинтересованы в первую очередь в исполнении директив вышестоящего начальства, которые заняты обеспечением стабильной работы отечественной экономики. Другой вопрос, что по своей структуре российская экономика (особенно промышленность, а также сектора эксплуатации природных ресурсов) довольно далека от западных и даже мировых стандартов «экологичности». Вместе с тем экологическое поведение требует «низовой организации», способной в той или иной степени аккумулировать импульсы гражданского общества.
Экологическое поведение, направленное на защиту собственного здоровья и здоровья окружающих, входит в число базовых потребностей человека. Вместе с тем между государством и представителями гражданского общества могут возникать разногласия по вопросу реализации экологической политики применительно к различным ситуациям. В данной связи важно отметить, что российская молодёжь далеко не полностью доверяет национальным государственным институтам, особенно тем, которые призваны всячески защищать гражданские права. В частности, Ф.Э. Шереги отмечает, что «молодёжь, придерживающаяся мнения, что её права защищены слабо или не защищены, сомневается в том ( $60 \%$ среди этой категории молодёжи), что Российская Федерация - это правовое государство» [2, с. 62], поэтому можно говорить о том, что и на пути экологических инициатив граждан сохраняется угроза превращения последних в протестную и оппозиционную деятельность.

Барьеры экологического поведения молодёжи в контексте особенностей институциональной среды российского общества. В целом экологическое поведение молодёжи не в последнюю очередь зависит от планомерных инвестиций в человеческий капитал, которые в России существенно отстают от темпов инвестиций в человеческий капитал наиболее развитых и развивающихся стран мира. В свою очередь человеческий капитал во многом определяется уровнем здоровья и экологической защищенности граждан. Так, например, по уровню эффективности медицины Россия уже занимает примерно 53-е место в мире [3], что свидетельствует о неудачах на пути реформирования системы здравоохранения. В данной связи исследователи отмечают, что «продолжительность 
жизни сейчас - 72 года, развитые страны прошли эту отметку на 45 лет раньше. При этом современная “оптимизация" здравоохранения не приводит к снижению смертности в стране» [4, с. 101]. Ясно, что продолжительность жизни напрямую связана как с экологическим поведением предшествующих поколений, так и с общими (накопленными) условиями жизни и функционированием институтов здравоохранения, качеством предоставляемых ими услуг. В будущем станет понятно, сможет ли экологическое поведение современной российской молодёжи и те экологические практики, в которые они включены, оказать влияние на рост продолжительности жизни в будущем.

Ведущие отечественные институты, включая государство, образование, гражданское общество и средства массовой информации не обладают соответствующим уровнем координации, способным направить общие усилия на формирование экологической культуры. Не секрет, что многие «независимые» экологические объединения и активисты воспринимаются как оппозиционеры или прямые противники решений, реализуемых на государственном уровне. Зачастую лидеры экологических протестов как бы автоматически записываются властями в провокаторы, которые стремятся к дестабилизации сложившейся ситуации. При этом в политическом пространстве страны не существует сколько-нибудь значимой (институционализированной) парламентской (системной) оппозиции, выступающей с понятных экологических позиций.

Современное состояние ряда институтов, обеспечивающих инвестиции в человеческий капитал, оставляет желать лучшего, поэтому и соответствующие барьеры экологического поведения обнаруживаются в институциональной сфере функционирования современного российского общества. Речь соответственно идет о том, что так называемая институциональная среда по-прежнему остаётся «ахиллесовой пятой» российской экономики, которой не хватает соответствующих правовых практик, способных поддержать экономический рост и в целом выступать важным регулятором соответствующих трансакций. Качество институтов самым непосредственным образом влияет на кон- курентоспособность российской экономики в целом и ставит преграды для ее дальнейшего развития в сторону экологизации. «Россия по качеству институтов находится на 88-м месте среди 138 стран (GCR 2016). Несмотpя на наблюдающуюся в последнее время положительную динамику (продвижение до 133-го места в GCR 2012-2013), ситуация с институтами ещё далека от удовлетворительной» [5, с. 233]. Отсюда следует, что существенным сдвигам в экологическом поведении молодёжи должны предшествовать институциональные реформы даже в тех областях общественной жизни, которые не связаны с экологией напрямую.

Многие интенции российских граждан по-прежнему в должной мере не удовлетворены современным российским государством, особенно те из них, которые находятся в плоскости правовых инстанций и, следовательно, решений, прописанных непосредственно в официальных законах. Экологические права личности выходят на передний план, когда речь заходит о том, чтобы сам человек заботился о собственном здоровье, но при этом общество должно создавать для этого соответствующие условия. «Важнейший запрос россиян в отношении государства - поиск оптимальных форм соотношения личной самореализации индивида и удовлетворения его базовых запросов, в том числе на благополучие, безопасность, правовую защищенность» [6, с. 60]. Реализация вышеописанных запросов не может быть решена без мониторинга экологических проблем и наличия довольно развитого экологического самосознания подрастающего поколения.

Правовые нормы как на уровне формальных, так и неформальных институтов могут регулироваться самим обществом, если оно будет способно относительно самостоятельным образом реализовывать экологические инициативы. Вместе с тем экологическая повестка должна быть актуализирована на уровне муниципалитетов и местных управляющих компаний. Очевидно, что высшим органам страны приходится заниматься мусорной проблемой в регионе, тогда как на местном уровне тяжело решить довольно простую на первый взгляд проблему. «Формирование экологической культуры напрямую связано 
с социокультурными изменениями общества в целом, невозможными без эффективной работы института образования, средств массовой информации и иных институтов социализации, четко выраженной политической воли и экономико-правовых изменений» [7, c. 365]. Важно также отметить необходимость практической реализации правовых норм в отношении правонарушений экологического характера, в особенности тех, которые пользуются поддержкой коррумпированных сотрудников администрации.

Современный отечественный бизнес, а речь идёт о наиболее крупных российских корпорациях, не спешит внедрять высокие экологические стандарты в собственные проекты, не испытывая при этом никакого давления со стороны гражданских активистов, а также региональных правительств, заинтересованных в поддержке местных избирателей (и реально отвечающих перед ними), поэтому к барьерам экологического поведения молодёжи в России можно отнести слабую ответственность государственных и частных корпораций (бизнес-групп, аффилированных с государством) в отношении общества и окружающей среды, что показали катастрофы техногенного свойства, например, происходившие в недавнем прошлом на российском Севере [8].

В данной связи исследователи отмечают, что сырьевая экономика страны, основанная на природной ренте, добыче и экспорте полезных ископаемых, откладывает крайне негативный отпечаток на среду обитания. Речь, конечно же, идёт в первую очередь о тех регионах страны, где эта добыча осуществляется, но при этом именно эти локации в значительной степени формируют экологический образ России на международной арене. «Сейчас в России сохранение экспортно-сырьевого экономического роста связано с увеличением загрязнения и деградации среды, нарушением баланса биосферы, что ведет к ухудшению здоровья человека и ограничивает возможности дальнейшего развития человеческого потенциала. Это означает, что страдает экологическая компонента качества жизни, благосостояния населения. Приближенные оценки рисков от загрязнения воды и воздуха позволяют говорить о том, что экономические издержки для здоровья населе- ния России, связанные с загрязнением воздуха и воды, составляют в среднем не менее 4-6\% от ВВП» [9, с. 19]. Вполне очевидно, что в данной связи существенно затруднены инвестиции в человеческий капитал, поскольку наличие вредных производств и их отходов существенно повышает рост хронических заболеваний.

Мы уже отмечали, что в последние годы серьезную угрозу для экологической ситуации во многих регионах страны представляет так называемая «мусорная проблема». Вместе с тем она может выступать дополнительным источником для стимуляции экологического поведения молодёжи, особенно в его протестном варианте. В целом нерешенность проблем с отходами и отсутствие соответствующей культуры сортировки мусора в ещё большей степени тормозит внедрение высоких экологических стандартов. В последнее время в стране появлялись новые очаги мусорных загрязнений, вызванные разрастанием мусорных свалок [10]. Однако территориальная разобщенность препятствует гражданам сформировать более тесные объединения, не говоря уже о том, что многие районы со сложной экологической ситуацией практически изолированы от густонаселенных регионов страны.

Основные барьеры экологического поведения российской молодёжи: социально-экономические аспекты. В настоящее время ряд социологических маркеров демонстрируют отсталость экологической культуры российского общества, что проявляется как недостаточная осознанность глобальной экологической повестки. Многие аспекты экологического сознания и мышления в терминах экологической безопасности ещё полностью не актуализированы в отечественной культуре и социальных практиках населения. Можно сказать, что в стране по-прежнему наблюдается дефицит экологической солидарности как между гражданами внутри страны, так и в целом с жителями всей планеты [11]. Сложившаяся ситуация не в последнюю очередь связана с историческим опытом местных экологических движений и отсутствием реальных политических партий экологической направленности, представленных в парламенте. 
Несмотря на развитие сети интернет, официальные СМИ, в частности, телевидение, не в полной мере информируют граждан о возникающих экологических угрозах, многие из которых продолжают носить по сути дела перманентный характер. Недостаток официальной информации об экологических проблемах зачастую заполняют оппозиционные ю-туб блогеры, которые в свою очередь также не специализируются на экологической проблематике, а используют эту тему в целях получения сиюминутного резонанса («хайпа»). Значительную роль в сложившейся ситуации во многом играют государственные СМИ, которые подают экологические проблемы в определенном свете с целью «защитить» Россию (от критики разнообразных экологических, в первую очередь международных организаций) и представить нашу страну в качестве крупнейшей энергетической державы и крупнейшего экспортера углеводородов. Можно сказать, что базис российской экономики детерминирован добычей и экспортом соответствующих полезных ископаемых. Более того, в ближайшие годы, особенно в условиях нарастания санкционного режима, вряд ли возможна перестройка российской экономики в сторону качественного роста так называемых «зеленых технологий» и принципиально нового экономикоэкологического уклада. По-прежнему природная рента и ориентация на неё выступает ключевой (базисной) детерминантой отечественной «колеи развития».

Ситуация вокруг водных ресурсов страны в целом далека от катастрофы, но пристальное изучение отдельных регионов даёт основание существенно задуматься над обнаруживаемой проблемой. При этом важно учитывать, что проблема чистой и питьевой воды входит в число наиболее опасных планетарных рисков для всех жителей земли наряду с разрушением озонового слоя и глобальным потеплением. «Суммарный дефицит водных ресурсов в маловодные годы в целом по стране, исходя из водохозяйственных балансов, оценивается в объеме 14,3 км ${ }^{3}$ (23\%). В ряде регионов, по оценкам Росводресурсов, невозможно решить эту проблему только за счет строительства новых водохранилищ, сезонного и многолетнего регулирования стока. В Республике Калмыкия, Ставрополь- ском и Краснодарском краях, в Кемеровской области, на Южном Урале для удовлетворения потребности в воде необходима ее подача из более водообеспеченных регионов. К регионам с низкой водообеспеченностью относятся: Ставропольский край, Заволжье, Нижнее Поволжье, юг Западной Сибири, Забайкалье, Центральная Якутия» [12, с. 29]. Водные ресурсы страны, в особенности крупнейшие реки (Дон, Волга и др.), продолжают находиться в ситуации, близкой к экологическому бедствию. Подобная ситуация в большей степени становится заметна в регионах страны, что негативных образом влияет на экологическую социализацию молодёжи в целом. Более того, молодые люди - жители регионов - осознают, что решение даже вполне локальных экологических проблем не может обойтись без директив федерального центра.

Вместе с тем в отдельных регионах страны уже наблюдается дефицит рекреационных ресурсов, а борьба с засушливостью почвы требует внедрения новых технологий. Таким образом, экологическая проблематика в стране связана не только с выбросом вредных веществ, но и с процессами глобальных климатических изменений, связанных с «хрупкостью» планетарной экосистемы. К тому же многие реки протекают по территории сопредельных стран, которые могут довольно враждебно относиться к политическому курсу современной России. В сложной ситуации вокруг водных ресурсов страны также негативную роль играют внешнеполитические факторы, не в последнюю очередь связанные с ситуацией вокруг недавно присоединенных к России территорий, поэтому в данной связи нельзя полностью исключать экологические диверсии со стороны других (враждебных) России государств.

Итак, многие угрозы экологического развития страны коренятся в геополитических вызовах и подпитываются конфликтами вокруг «спорных» территорий. Дефицит пресной воды является, например, одним из важных барьеров, создающих, в частности, сложности для сельскохозяйственного развития республики Крым. «Воссоединение Крыма с Россией в 2014 г. увеличило число таких регионов и вместе с тем показало, что трансграничные водные ресурсы могут быть использованы как оружие при возникновении 
политических конфликтов. Украина перекрыла поступление воды по каналу из Днепра на полуостров, что привело к экономическому ущербу: погибли посевы риса и другие сельскохозяйственные культуры» [12, с. 29]. Стало ясно, что далеко не все экологические проблемы в стране, угрожающие безопасности российских граждан, связаны с действиями местных властей и отсутствием управленческих компетенций внутри страны, поэтому и экологическое поведение молодёжи, особенно в таком регионе, как Крым, должно вбирать в себя оповещения о внешних угрозах экологической безопасности.

Возвращаясь к структурному описанию отечественной экономики, вернее, её базиса, необходимо указать на существенную задержку в её развитии, которое существенно отстаёт от мировых трендов. Таким образом, драйверы отечественной экономики по-прежнему сосредоточены в добывающем секторе. В данной связи исследователи вполне справедливо рассуждают о том, что без становления в стране полноценной «зеленой экономики» будет очень тяжело сформировать паттерны экологического поведения, способные удовлетворить высоким институциональным и технологическим стандартам жизни. Вместе с тем нельзя недооценивать и тот запрос, который имеется в обществе на так называемое «зеленое» потребление.

Таким образом, экологический консюмеризм может выступать своеобразным драйвером «зеленой экономики», но, пожалуй, он будет наиболее эффективным в случае развития и инвестирования в новые источники энергии. Вместе с тем экологическое поведение граждан будет выглядеть довольно однобоким в том смысле, если они не будут проявлять экологическую активность в своём повседневном быту. «С практической точки зрения, учитывая нынешнее экологическое поведение граждан, мы можем сделать единственный вывод: без “зеленой экономики" не будет экологического поведения, а без экологического поведения - не будет “зеленой экономики”. Очевидно, что многое может измениться в лучшую сторону, если граждане смогут убедиться (не поверить на слово, а именно убедиться) в тесной связи экологического поведения и качества жизни» $[13$, с. 64]. Более того, качество жизни долж- но восприниматься не как редкий дар или удача, а норма российской жизни, но этого невозможно достичь без качественного роста благосостояния широких слоёв российского населения (и качественного роста представителей среднего класса), причём в сложных экономических условиях (преимущественного социального выживания и адаптации) в особенно сложной экономической ситуации оказываются зависимые от родителей молодые люди.

С другой стороны, если речь заходит о наиболее критических и сложных экологических ситуациях, то молодым людям всё-таки оказывается намного проще покинуть локации, неблагоприятные с точки зрения экологии. Следовательно, одним из трендов экологического поведения молодёжи становится «бегство» из экологически неблагополучных регионов, преимущественно в столичные города и крупные городские агломерации, которые, однако, также не свободны от загрязнения среды обитания и вредных выбросов в атмосферу. При этом попытки заманить профессиональную молодёжь (молодых специалистов) в сельскую местность с довольно приемлемыми экологическими условиями по-прежнему в целом оказываются малоэффективными.

Таким образом, в российском обществе, то есть в структуре его восприятия глобальных экологических вызовов, далеко не всем из них придаётся какое-либо серьезное значение. В первую очередь это касается осознания климатических изменений, которые являются существенными угрозами экологической стабильности. В данной связи исследователи отмечают, что в российском обществе «фиксируется самая слабая корреляционная связь между убежденностью в том, что климат меняется, и обеспокоенностью такими изменениями, а также между обеспокоенностью изменениями климата и оценкой их последствий. Можно утверждать, что в целом обеспокоенность изменением климата не рассматривается россиянами как значимая информация для модификации повседневного поведения» [7, с. 364]. Многие россияне полагают, что эта проблема спущена даже враждебными силами, чему активно способствуют средства массовой информации. Сложившаяся ситуация во многом объясняется стереотипами 
россиян в отношении «глобального потепления», которое даже в условиях довольно сурового северного климата воспринимается в массовом сознании как некоторое «позитивное» явление, способное в перспективе привести к росту теплых и солнечных дней в году. Кроме всего прочего, многие люди традиционно полагают, что Россия является настолько северной и холодной страной, что проблемы, связанные с глобальным потеплением, попросту её не касаются.

Экологические ценности по-прежнему не являются доминирующими в российском социуме, а если и воспринимаются, то как привилегии высших классов, а не как преимущества хотя бы образованных и средних групп населения. При этом ценность экологической среды для большей части жителей страны не включена в поле повседневного восприятия собственных гражданских прав, а борьба или даже повседневный мониторинг экологических проблем воспринимаются сквозь призму эксклюзивности. Однако на локальном и прежде всего городском уровне организованные граждане вполне могут защитить свою среду обитания, особенно, когда речь заходит о сохранении зеленых насаждений. Тем не менее, (несмотря на локальные успехи) рядом исследователей вполне справедливо делается вывод о том, «что формирование экологической культуры в современной России предполагает необходимость глубинных изменений на уровне индивидуальных и коллективных картин мира как простых граждан, так и лиц, принимающих решения. Эти изменения должны основываться на включении в систему ценностей экологического императива в качестве ее фундаментального конструкта» [7, с. 365]. Однако нравственные действия и поведение молодежи должны быть основаны на прагматическом видении мира сквозь призму, в том числе личных с оциальных достижений и карьерных возможностей.

Заключение. К числу ключевых барьеров, существенно тормозящих развитие экологического поведения в среде российской молодёжи, необходимо отнести структурные детерминанты российской экономики, не в последнюю очередь связанные с системными проблемами её модернизации. Важ- но понимать, что экологическое поведение, особенно рассмотренное сквозь призму его рациональной составляющей, должно быть в значительной степени вписано в экономический этос большей части населения страны [14], поэтому приоритетной в сложившейся ситуации является выработка у подрастающего поколения некого «экологического рефлекса», подкрепленного знаниями в области экологии и стратегическим мышлением. Оказывается, что зачастую молодой человек поступает экологичным образом не только в тот момент, когда отправляется в романтическое путешествие (в лес) на лоно природы, но когда в своей повседневной практике выбирает тот или иной продукт, услуги или сортирует собственный мусор в процессе деятельности собственного домохозяйства. В обществе попрежнему наблюдается дефицит экологической солидарности в решении ряда проблем, связанных с охраной окружающей природы и среды обитания. По-прежнему в российском обществе не в полной мере может быть реализована глобальная экологическая повестка, вернее, экологическая повестка, актуальная для наиболее развитых стран, например, Европейского союза. Таким образом, оказывается, что реальная экологическая повестка напрямую связана с тем положением, которое занимает та или иная страна в мировом разделении труда. Соответственно, далеко не все государства, тем более страны, ориентированные на природную ренту, могут позволить себе высокий уровень внедрения экологических проектов, способных выступать в качестве крупнейших инфраструктурных проектов.

На сегодняшний день государственная стратегия России, несмотря на целый ряд деклараций экологического характера, всё-таки в большей степени нацелена на адаптацию в условиях санкционного режима и сохранения статуса страны в качестве крупнейшего экспортера углеводородов. Более того, существует (на наш взгляд, в целом ошибочное) мнение, что «чрезмерная» экологизация («озеленение») отечественной экономики может привести к ослаблению военно-геополитического влияния России в мире и на постсоветском пространстве. По крайней мере, величие страны, о котором много говорят в центральных СМИ, не исчерпывается её впечатляющей 
обороноспособностью, а предполагает реализацию инфраструктурных проектов экологического характера. Под такими проектами не стоит понимать только лишь развитие парков в крупных городах, где они естественно необходимы, это очистка рек, спасение лесов и сокращение вредных выбросов в атмосферу. Пожалуй, что экологические изменения в России ещё не являются ощутимыми и с трудом могут быть визуализированы в повседневной практике молодёжи.

\section{Литература}

1. Казиева А.К. Преграды на пути развития экологического строительства в России// Гуманитарные научные исследования. 2015. - №12 (52). - C. 341-344.

2. Шереги Ф.Э. Российская молодежь: настроение, ожидания, ценностные ориентации. - М.: Центр социального прогнозирования и маркетинга, 2013.

3. Рейтинг стран мира по уровню здравоохранения (Bloomberg Health Care Efficiency за 2018 год) [Электронный ресурс] — Peжим доступа: https://nonews.co/directory/lists/ countries/health (Дата обращения: 10.08.2020).

4. Регент T. М. Потенциалы человеческого капитала и цифровой экономики России // Вестник Российского нового университета. Серия: Человек и общество. - 2018. - №1.

5. Травин Д., Гельман В., Заострецеев A. Российский путь: Идеи, Интересы, Институты, Иллюзии. - СПб., 2017.

6. Зарубина Н.Н. Историческая память как источник знаний о цивилизационной специфике России // Общественные науки и современность. - 2017. — №2.

7. Курбанов А.Р., Прохода В.А. Экологическая культура: эмпирическая проекция (отношение россиян к изменению климата) // Мониторинг общественного мнения: экономические и социальные перемены. 2019. - №4 (152). - C. 347-370.

8. «Озеро уже мертвое». В РАН рассказали о последствиях экологической катастрофы в Норильске [Электронный ресурс] Режим доступа: https://life.ru/p/norilskekologicheskaya-katastrofa (Дата обращения: 11.08.2020).

9. Бобылев С.Н., Минаков В.С., Соловьёва С. В., Третьяков В.В. Эколого-экономи- ческий индекс регионов РФ. Методика и показатели для расчета. - М., 2012.

10. Почему в России буксует мусорная реформа? [Электронный ресурс] Режим доступа: https://www.rosbalt.ru/ piter/2020/02/17/1817629.html (Дата обращения: 15.08.2020).

11. Тихомиров Д.А., Кисткина И.А. Проблема осознания экологической угрозы в России // Горизонты гуманитарного знания. 2017. — №2. - С. 55-61.

12. Василенко В.A. Экологические угрозы экономике России // Мир новой экономики. - 2014. - №3. - С. 21-31.

13. Сосунова И.А., Мамонова О.Н. Экологическое поведение граждан и качество жизни в условиях глобализации // Философия и социальные науки. - 2011. - №3/4. - С. 62-66.

14. Нигматуллина Р.М., Шараванд М. Экологическая этика как фактор разрешения экологических кризисов // Вестник экономики, права и социологии. - 2014. - №4. C. 243-246.

\section{References}

1. Kazieva A.K. Pregrady na puti razvitija jekologicheskogo stroitel'stva $\mathrm{v}$ Rossii [Barriers to the development of ecological construction in Russia] // Gumanitarnye nauchnye issledovanija [Humanitarian scientific research]. - 2015. №12 (52). - Pp. 341-344.

2. Sheregi F. Je. Rossijskaja molodezh': nastroenie, ozhidanija, cennostnye orientacii [The Russian youth: mood, expectations, and value orientations]. - Moscow: Centr social'nogo prognozirovanija i marketinga, 2013.

3. Rejting stran mira po urovnju zdravoohranenija (Bloomberg Health Care Efficiency za 2018 god) [The ranking of countries in terms of public health (Bloomberg Health Care Efficiency for 2018)] [Jelektronnyj resurs] URL: https://nonews.co/directory/lists/countries/health (Date accessed: 10.08.2020).

4. Regent T.M. Potencialy chelovecheskogo kapitala i cifrovoj jekonomiki Rossii [Potentials of human capital and digital economy of Russia] // Vestnik Rossijskogo novogo universiteta. Serija: Chelovek i obshhestvo [Bulletin of the Russian new University. Series: Man and society]. — 2018. — №1. 
5. Travin D., Gel'man V., Zaostrecev A. Rossijskij put': Idei, Interesy, Instituty, Illjuzii [The Russian way: Ideas, Interests, Institutions, Illusions]. - Saint-Petersburg, 2017.

6. Zarubina N.N. Istoricheskaja pamjat' kak istochnik znanij o civilizacionnoj specifike Rossii [Historical memory as a source of knowledge about the civilizational specifics of Russia] // Obshhestvennye nauki i sovremennost' [Social Sciences and modernity]. - 2017. - №2.

7. Kurbanov A.R., Prohoda V.A. Jekologicheskaja kul'tura: jempiricheskaja proekcija (otnoshenie rossijan k izmeneniju klimata) [Ecological culture: an empirical projection (the attitude of Russians to climate change)] // Monitoring obshhestvennogo mnenija: jekonomicheskie i social'nye peremeny [Monitoring of public opinion: economic and social changes]. 2019. — №4 (152). — Pp. 347-370.

8. «Ozero uzhe mertvoe». V RAN rasskazali o posledstvijah jekologicheskoj katastrofy v Noril'ske [«The Lake is already dead». The Russian Academy of Sciences told about the consequences of the ecological disaster in Norilsk] [Jelektronnyj resurs] — URL: https://life. $\mathrm{ru} / \mathrm{p} /$ norilsk-ekologicheskaya-katastrofa (Date accessed: 11.08.2020).

9. Bobylev S.N., Minakov V.S., Solov'jovaS. V., Tret'jakov V. V. Jekologo-jekonomicheskij indeks regionov RF. Metodika i pokazateli dlja rascheta [Ecological and economic index of regions of the Russian Federation. Methodology and indicators for calculation]. - Moscow, 2012.

10. Pochemu v Rossii buksuet musornaja reforma? [Why is the garbage reform stalling in Russia?] [Jelektronnyj resurs] — URL: https:// www.rosbalt.ru/piter/2020/02/17/1817629.html (Date accessed: 15.08.2020).

11. Tihomirov D.A., Kistkina I.A. Problema osoznanija jekologicheskoj ugrozy v Rossii [The Problem of awareness of the environmental threat in Russia] // Gorizonty gumanitarnogo znanija [Horizons of humanitarian knowledge]. - 2017. — №2. - Pp. 55-61.

12. Vasilenko V.A. Jekologicheskie ugrozy jekonomike Rossii [Environmental threats to the economy of Russia] // Mir novoj jekonomiki [World of the new economy]. - 2014. - №3. - Pp. 21-31.

13. Sosunova I.A., Mamonova O.N. Jekologicheskoe povedenie grazhdan i kachestvo zhizni v uslovijah globalizacii [Environmental behavior of citizens and quality of life in the conditions of globalization] // Filosofija i social'nye nauki [Philosophy and social Sciences]. 2011. — №3/4. — Pp. 62-66.

14. Nigmatullina R.M., Sharavand M. Jekologicheskaja jetika kak faktor razreshenija jekologicheskih krizisov [Environmental ethics as a factor in resolving environmental crises] // Vestnik jekonomiki, prava i sociologii [Bulletin of Economics, law and sociology]. — 2014. №4. - Pp. 243-246. 


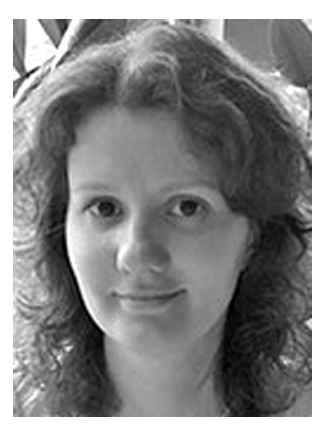

Захарова Вера Александровна — кандидат философских наук, старший научный сотрудник Крымского филиала Федерального научно-исследовательского социологического центра Российской академии наук. Специалист в области исследования экоправового воспитания, экологических практик и экологического поведения. Соисполнитель ряда региональных социологических исследований.

Zakharova Vera Alexandrovna - Candidate of Philosophical Sciences, Senior Researcher, Crimean Branch of the Federal Research Sociological Center, Russian Academy of Sciences. Specialist in the field of environmental education research, environmental practices and environmental behavior. Co-executor of a number of regional sociological studies.

295021, г. Симферополь, ул. им. газеты «Крымская правда», 4 4 st. Name of the Newspaper «Crimean Truth», 295021, Simferopol, Russia E-mail: zakharova7vera@mail.ru 